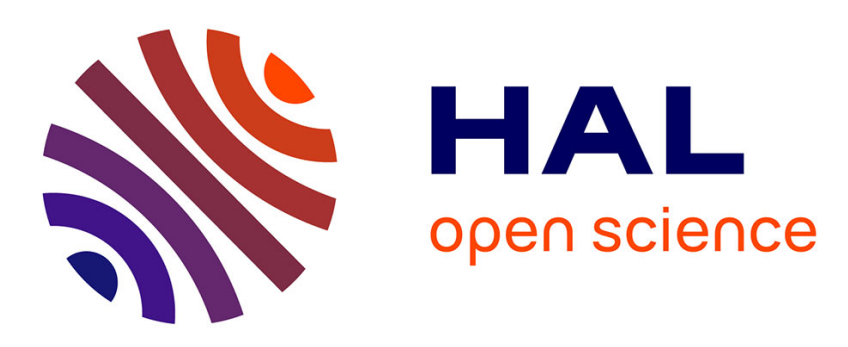

\title{
Magnetic and structural properties of the Fe layers in $\mathrm{CoO} / \mathrm{Fe} / \mathrm{Ag}(001)$ Heterostructure
}

Rantej Bali, Marcio Soares, Aline Y. Ramos, Hélio Tolentino, Fikret Yildiz,

Clémence Boudot, Olivier Proux, Maurizio de Santis, Marek Przybylski, Jürgen Kirschner

\section{To cite this version:}

Rantej Bali, Marcio Soares, Aline Y. Ramos, Hélio Tolentino, Fikret Yildiz, et al.. Magnetic and structural properties of the Fe layers in $\mathrm{CoO} / \mathrm{Fe} / \mathrm{Ag}(001)$ Heterostructure. Applied Physics Letters, 2012, 100 (13), pp.132403. 10.1063/1.3695158 . hal-00682934

\section{HAL Id: hal-00682934 \\ https://hal.science/hal-00682934}

Submitted on 27 Mar 2012

HAL is a multi-disciplinary open access archive for the deposit and dissemination of scientific research documents, whether they are published or not. The documents may come from teaching and research institutions in France or abroad, or from public or private research centers.
L'archive ouverte pluridisciplinaire HAL, est destinée au dépôt et à la diffusion de documents scientifiques de niveau recherche, publiés ou non, émanant des établissements d'enseignement et de recherche français ou étrangers, des laboratoires publics ou privés. 


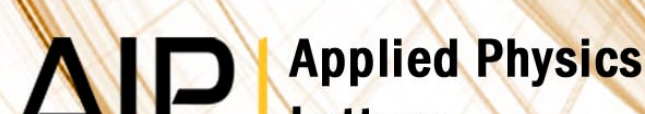 \\ Letters}

\section{Magnetic and structural properties of the Fe layers in CoO/Fe/Ag(001) heterostructure}

Rantej Bali, Márcio M. Soares, Aline Y. Ramos, Hélio C. N. Tolentino, Fikret Yildiz et al.

Citation: Appl. Phys. Lett. 100, 132403 (2012); doi: 10.1063/1.3695158

View online: http://dx.doi.org/10.1063/1.3695158

View Table of Contents: http://apl.aip.org/resource/1/APPLAB/v100/i13

Published by the American Institute of Physics.

\section{Related Articles}

Tailoring interfacial exchange coupling with low-energy ion beam bombardment: Tuning the interface roughness Appl. Phys. Lett. 100, 122409 (2012)

Breakdown by magnetic field in a La0.7Sr0.3MnO3/MgO/Fe spin valve Appl. Phys. Lett. 100, 122408 (2012)

Fabrication of ultrathin L10-FePt based exchange coupled composite media J. Appl. Phys. 111, 07B732 (2012)

Effect of Si interlayers on the magnetic and mechanical properties of $\mathrm{Fe} / \mathrm{Ge}$ neutron polarizing multilayer mirrors J. Appl. Phys. 111, 063904 (2012)

Exchange biased CoFeB-MgO tunnel junctions at the onset of perpendicular anisotropy with in-plane/out-ofplane sensing capabilities

J. Appl. Phys. 111, 053930 (2012)

\section{Additional information on Appl. Phys. Lett.}

Journal Homepage: http://apl.aip.org/

Journal Information: http://apl.aip.org/about/about_the_journal

Top downloads: http://apl.aip.org/features/most_downloaded

Information for Authors: http://apl.aip.org/authors

\section{ADVERTISEMENT}

NEW!

iPeerReview

AlP's Newest App
Authors...

Reviewers...

Check the status of

submitted papers remotely!

ADPublishing 


\title{
Magnetic and structural properties of the Fe layers in $\mathrm{CoO} / \mathrm{Fe} / \mathrm{Ag}(001)$ heterostructure
}

\author{
Rantej Bali, ${ }^{1, a)}$ Márcio M. Soares, ${ }^{2, b)}$ Aline Y. Ramos, ${ }^{2}$ Hélio C. N. Tolentino, ${ }^{2}$ \\ Fikret Yildiz, ${ }^{1, \mathrm{c})}$ Clemence Boudot, ${ }^{2}$ Olivier Proux, ${ }^{3}$ Maurizio De Santis, ${ }^{2}$ \\ Marek Przybylski, ${ }^{1}$ and Jürgen Kirschner ${ }^{1}$ \\ ${ }^{1}$ Max-Planck-Institut für Mikrostrukturphysik, 06120 Halle, Germany \\ ${ }^{2}$ Institut Néel, CNRS and Université Joseph Fourier, BP 166, F-38042 Grenoble Cedex 9, France \\ ${ }^{3}$ Observatoire des Sciences de l'Univers-OSUG-Grenoble, F-38051 Grenoble, France
}

(Received 8 December 2011; accepted 29 February 2012; published online 26 March 2012)

\begin{abstract}
The influence of interfacial oxidation on the magnetic behaviour of $\mathrm{CoO}$ covered $\mathrm{Fe} / \mathrm{Ag}(001)$ is reported. Coverage with $\mathrm{CoO}$ causes the formation of a mixed $\mathrm{Fe}_{2} \mathrm{O}_{3}-\mathrm{Fe}_{3} \mathrm{O}_{4}$ interfacial oxide layer. The depth of the Fe-oxide varies with the thickness of pre-covered Fe and above 8 monolayers (MLs) of Fe the oxide depth becomes constant at 2 ML. Differences in exchange bias and coercivity obtained from magnetic field and zero field cooling nearly vanish above 8 ML Fe thickness, showing a direct correlation between the magnetic behaviour of $\mathrm{Fe}$ and structure of the interfacial Fe-oxide layer. (C) 2012 American Institute of Physics. [http://dx.doi.org/10.1063/1.3695158]
\end{abstract}

Exchange coupling between thin films of an antiferromagnet (AFM) and a ferromagnet (FM) in proximity to each other is sensitive to the quality of the interface. ${ }^{1}$ Defects such as intermixing and interfacial roughness affect the magnitude and direction of AFM/FM exchange coupling. Several oxides of $3 d$ transition metals are antiferromagnetic and due to their robust spin-structure are employed as model systems to induce exchange bias in metallic FMs. In these systems in addition to the roughness and intermixing there is also the possibility of oxidation of the ferromagnetic layer due to diffusion or during growth of the oxide film. ${ }^{2,3}$ The interfacial oxide layer can lower the exchange bias but may also influence the anisotropy of the ferromagnetic layer. The influence of interfacial oxides on the anisotropy is also relevant to magnetic tunnel junctions where oxide layers are used as tunnel barriers. ${ }^{4}$

The weakening of exchange bias due to partial oxidation of the metallic FM coupled to an oxide AFM has been investigated previously. However, much less is known on the influence of the interfacial oxide on the anisotropy of the FM. An ideal system to study the influence of interfacial oxide on exchange bias and anisotropy is the antiferromagnet $\mathrm{CoO}$ coupled with ferromagnetic $\mathrm{Fe}$ grown on $\mathrm{Ag}(001)$, i.e., $\mathrm{CoO} / \mathrm{Fe} / \mathrm{Ag}(001) .{ }^{5}$ This is due to the existence two spin orientations in uncovered $\mathrm{Fe} / \mathrm{Ag}(001)$ depending on the $\mathrm{Fe}$ thickness: the spins orient perpendicular to the film plane up to 4-5 monolayers (MLs) followed by a spin reorientation transition (SRT) such that in thicker Fe the moments show in-plane fourfold anisotropy with easy axes along $\mathrm{Fe}\langle 001\rangle .^{6-8}$ This enables the observation of the effect of the

\footnotetext{
a) Author to whom correspondence should be addressed. Electronic mail: rantej@gmail.com. Present address: Helmholtz-Zentrum Dresden-Rossendorf e.V., Institute of Ion Beam Physics and Materials Research, Dresden, Germany.

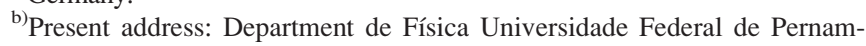
buco, 50670-901, Recife, PE, Brasil.

${ }^{c}$ Present address: Department of Physics, Gebze Institute of Technology, Gebze, Turkey.
}

$\mathrm{CoO}$ AFM layer and interfacial Fe-oxide on perpendicular and in-plane spin orientations of the $\mathrm{Fe} / \mathrm{Ag}(001)$.

We probed the influence of interfacial oxidation of $\mathrm{Fe}$ on the exchange bias $\left(\mathrm{H}_{\mathrm{ex}}\right)$ and anisotropy in $\mathrm{CoO} / \mathrm{Fe} /$ $\mathrm{Ag}(001)$ and report the thickness dependent regimes of magnetic behaviour in the Fe layers. We find that the thickness of the interfacial Fe-oxide is dependent on the thickness of pre-covered $\mathrm{Fe}$ and influences the $\mathrm{H}_{\mathrm{ex}}$ and coercivity $\left(\mathrm{H}_{\mathrm{c}}\right)$ of the Fe layer. Below a critical Fe thickness of $8 \mathrm{ML}$, the $\mathrm{H}_{\mathrm{ex}}$ and $\mathrm{H}_{\mathrm{c}}$ of the $\mathrm{CoO} / \mathrm{Fe}$ bi-layer are larger when exchange coupling is induced by applying a magnetic field whilst cooling through the Néel temperature $\left(T_{\mathrm{N}}\right)$ of the CoO. Above the critical thickness the differences in $\mathrm{H}_{\mathrm{ex}}$ and $\mathrm{H}_{\mathrm{c}}$ between cooling with and without field nearly vanish showing a direct correlation of the magnetic behaviour to the structure of the interfacial oxide.

Sample preparation was carried out in a multichambered ultra-high vacuum system with a base pressure better than $5 \times 10^{-10}$ mbar. An $8 \mathrm{~mm}$ in diameter $\operatorname{Ag}(001)$ crystal was cleaned by sputtering with $\mathrm{Ar}^{+}$at $1 \mathrm{keV}$ and annealing at $820 \mathrm{~K}$ for $30 \mathrm{~min}$. An Fe wedge sample was thermally deposited while a shutter was gradually introduced causing a gradient in the exposure of the substrate surface to the constant Fe flux. The thickness of the wedge $\left(t_{\mathrm{Fe}}\right)$ varied gradually over $5 \mathrm{~mm}$ from 0 to $10 \mathrm{ML}$ and then a $2 \mathrm{~mm}$ flat region of $15 \mathrm{ML}$ was grown to demarcate the end of the slope. The sample was covered with $1 \mathrm{ML}$ of metallic Co to protect the Fe wedge from oxidation. The sample was transferred under UHV to another chamber for reactive growth. The protective Co covering was restricted to $1 \mathrm{ML}$ to prevent any possible unoxidized Co layer in contact with Fe. Since $\mathrm{Fe}$ adlayers at least above $4 \mathrm{ML}$ are known to grow smooth on $\mathrm{Ag}(001)$, such 1 ML Co coverage is expected to provide a sufficient protection and limit Fe oxidation when the surface is exposed to oxygen. The sample was heated to $340 \mathrm{~K}$ and Co was evaporated under an $\mathrm{O}_{2}$ pressure of $5 \times 10^{-7}$ mbar. About $7 \mathrm{~nm}$ (33 ML) of $\mathrm{CoO}$ was grown in $25 \mathrm{~min}$. Such a $\mathrm{CoO}$ thickness is larger than the reported thickness above 
(a)

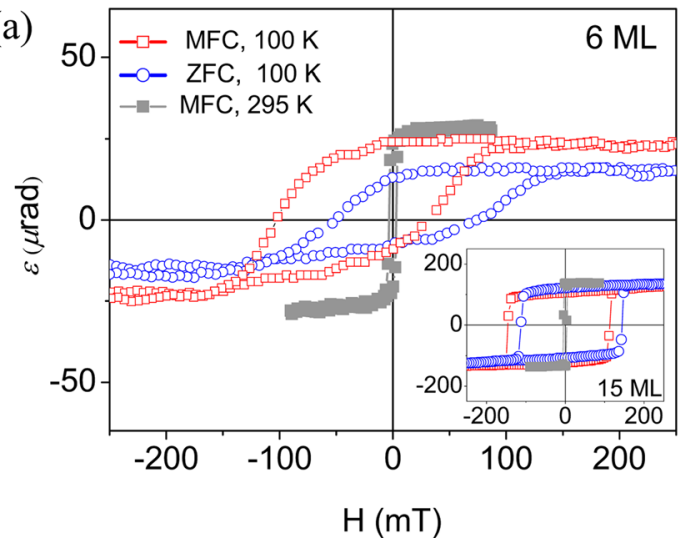

(b)

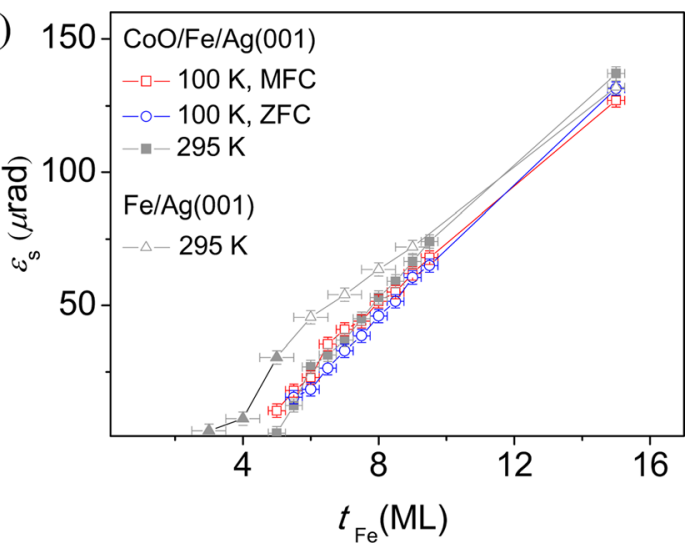

FIG. 1. (Color online) (a) Hysteresis loop for 6 ML Fe thickness plotted as Kerr ellipticity $(\varepsilon)$ vs applied field (H) in the longitudinal-MOKE geometry after magnetic field cooling, MFC (red squares) and zero field cooling, ZFC (blue circles) and in each case warming to $100 \mathrm{~K}$. The difference between the loops vanished at $295 \mathrm{~K}$ (solid squares). The inset shows the corresponding loops for $15 \mathrm{ML}$ Fe thickness. (b) The Kerr ellipticity in saturation ( $\left.\varepsilon_{\mathrm{s}}\right)$ was extracted from the hysteresis loops after the above sample cooling and warming procedures and plotted as a function of Fe thickness $\left(t_{\mathrm{Fe}}\right)$. Also shown is the $\varepsilon_{\mathrm{s}}\left(t_{\mathrm{Fe}}\right)$ for the asgrown Fe at $295 \mathrm{~K}$ (triangles) measured prior to the $\mathrm{CoO}$ deposition. Solid triangles indicate that the loops were not saturated and the values were extracted at $200 \mathrm{mT}$.

which $\mathrm{H}_{\mathrm{ex}}$ ceases to vary with the AFM thickness. ${ }^{9}$ The $\mathrm{CoO}$ surface seen in the low energy electron diffraction (LEED) pattern showed well-defined spots with an ordered cubic $(1 \times 1)$ surface. Ex situ grazing incidence X-ray diffraction showed that $\mathrm{CoO}$ was grown epitaxially with (001) surface planes and the $\mathrm{CoO}[110]$ axes parallel to the $\mathrm{Fe}[100]$ and $\mathrm{Ag}[110]$ axes. The $\mathrm{CoO}$ film was almost completely relaxed with lattice parameters $a=4.251 \AA$ and $c=4.242 \AA$, very close to the bulk $\mathrm{CoO}$ value of $4.260 \AA$.

Magneto-optic Kerr effect (MOKE) measurements were carried out at room temperature (RT) on the uncovered $\mathrm{Fe}$ wedge and at varying temperature after deposition of the $\mathrm{CoO}$, to plot Kerr ellipticity $(\varepsilon)$ against applied field $(\mathrm{H})$. The covered sample was studied in two situations: (a) after magnetic field cooling (MFC), with in-plane field, $\mathrm{H}_{\mathrm{mfc}}=+550 \mathrm{mT}$ applied parallel to the easy axis of the $\mathrm{Fe}$ $\left(\mathrm{H}_{\mathrm{mfc}}|| \mathrm{Fe}[001]\right)$, and (b) after zero field cooling (ZFC). ZFC was performed after measuring hysteresis loops of the precooled sample such that the last applied field was $-350 \mathrm{mT}$ putting the $\mathrm{Fe}$ layer at negative remanence during cooling. In each case, the sample was first heated to $350 \mathrm{~K}$ to ensure that the $T_{\mathrm{N}} \approx 290 \mathrm{~K}$ of $\mathrm{CoO}$ film (Ref. 10) was exceeded and then cooled down to $5 \mathrm{~K}$. Hysteresis loops were measured along $\mathrm{Fe}$ [001] after warming to 100 and $295 \mathrm{~K}$.

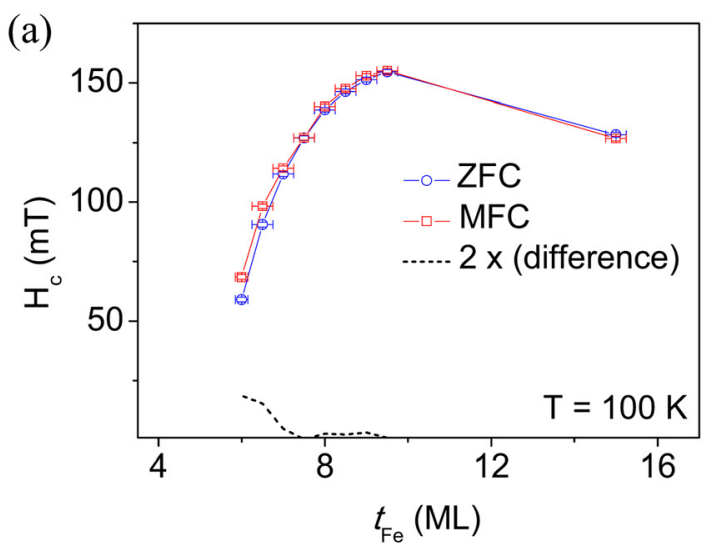

Figure 1(a) shows the longitudinal-MOKE hysteresis loops for $t_{\mathrm{Fe}}=6 \mathrm{ML}$ Fe measured after MFC and ZFC. The loop shifts are clearly observed at $100 \mathrm{~K}$ for both MFC and ZFC and are 35 and $7.5 \mathrm{mT}$, respectively. The inset of Fig. 1 (a) shows that the corresponding values at $t_{\mathrm{Fe}}=15 \mathrm{ML}$ are 17 and $16 \mathrm{mT}$, respectively. The sign of the loop shift depends on the direction of the FM magnetization during cooling, and it was oppositely oriented during the MFC and ZFC procedures. This was because $\mathrm{H}_{\mathrm{mfc}}$ was positive for MFC and the Fe remnant moment was negative during ZFC. At $295 \mathrm{~K}$ the hysteresis loops are independent of field cooling history and are nearly identical for MFC and ZFC because $\mathrm{T}>T_{\mathrm{N}}$. Compared to the $295 \mathrm{~K}$ measurements the coercive fields at $100 \mathrm{~K}$ are larger by a factor of 30 .

Figure 1(b) shows the dependence of the Kerr ellipticity at maximum applied field $\left(\varepsilon_{\mathrm{s}}\right)$ obtained and plotted as a function of $t_{\mathrm{Fe}}$. The $\varepsilon_{\mathrm{s}}\left(t_{\mathrm{Fe}}\right)$ were measured for uncovered and $\mathrm{CoO}$ covered $\mathrm{Fe} / \mathrm{Ag}(001)$. The $\varepsilon_{\mathrm{s}}\left(t_{\mathrm{Fe}}\right)$ measured prior to $\mathrm{CoO}$ coverage is linear for $t_{\mathrm{Fe}}>6 \mathrm{ML}$, and starts to deviate below this thickness. The sample exhibited a square loop typical of the easy axis at $t_{\mathrm{Fe}}=6 \mathrm{ML}$ while at $4 \mathrm{ML}$ could not be saturated at the maximum applied field $500 \mathrm{mT}$. The sample was saturated perpendicular to the film plane at fields of $200 \mathrm{mT}$ for $t_{\mathrm{Fe}}=4 \mathrm{ML}$ placing the SRT between 4 to $6 \mathrm{ML}$ in the Fe/

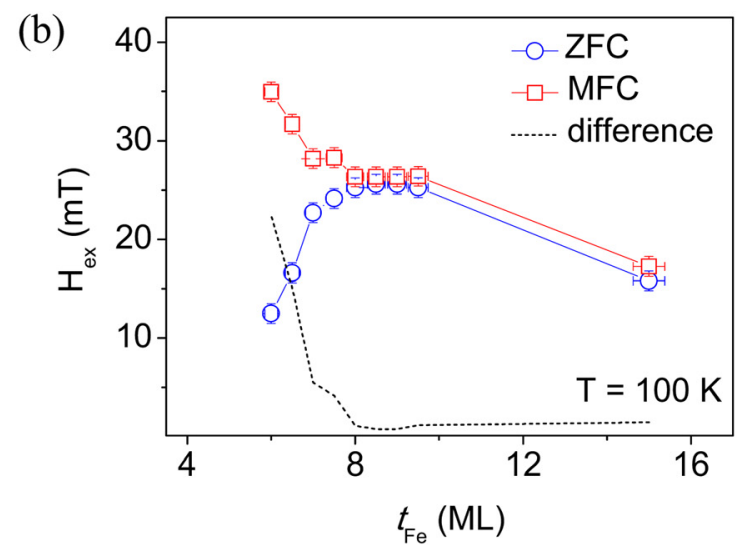

FIG. 2. (Color online) Dependence of (a) coercivity $\left(\mathrm{H}_{\mathrm{c}}\right)$ and $(\mathrm{b})$ exchange bias $\left(\mathrm{H}_{\mathrm{ex}}\right)$ on the nominal Fe thickness $\left(t_{\mathrm{Fe}}\right)$. The values were extracted from hysteresis loops measured after zero field cooling, ZFC (circles) and magnetic field cooling, MFC (squares) and warming to $100 \mathrm{~K}$. Dotted line in (a) shows two times the difference between the coercivities for MFC and ZFC. 


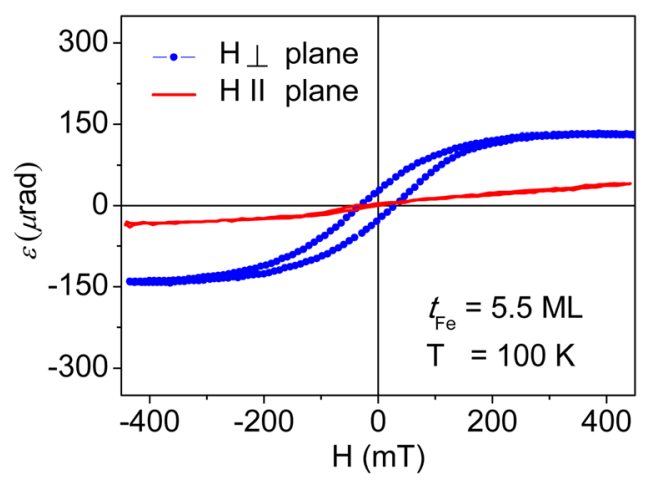

FIG. 3. (Color online) Hysteresis loops measured in the polar- and longitudinal-MOKE geometries for an Fe thickness of 5.5 ML after zero field cooling and warming to $100 \mathrm{~K}$.

$\operatorname{Ag}(001)$ sample. $^{6-8}$ The $\varepsilon_{\mathrm{s}}\left(t_{\mathrm{Fe}}\right)$ functions measured after CoO coverage are also shown. The MFC and ZFC data of the $\mathrm{CoO} / \mathrm{Fe} / \mathrm{Ag}(001)$ sample show large deviation from that of the uncovered $\mathrm{Fe} / \mathrm{Ag}(001)$. This deviation gradually reduces with increasing $\mathrm{Fe}$ thickness, and becomes nearly constant above $8 \mathrm{ML}$. For $t_{\mathrm{Fe}}<6 \mathrm{ML}$, the hysteresis loops were not saturated at the maximum applied field of $500 \mathrm{mT}$ and for $t_{\mathrm{Fe}}<4 \mathrm{ML}$, the magneto-optic signal becomes negligible within the applied field range.

The $\mathrm{H}_{\mathrm{c}}$ at $100 \mathrm{~K}$ for both ZFC and MFC situations (Fig. 2(a)) displays a similar behavior with increasing $t_{\mathrm{Fe}}$. The $\mathrm{H}_{\mathrm{c}}$ increases with $t_{\mathrm{Fe}}=6 \mathrm{ML}$ to $9 \mathrm{ML}$, and is seen to have decreased at $15 \mathrm{ML}$. For $t_{\mathrm{Fe}}=6 \mathrm{ML}$, the $\mathrm{H}_{\mathrm{c}}$ of the sample after MFC is larger by about $10 \mathrm{mT}$ than that after ZFC; this difference becomes negligible above $8 \mathrm{ML}$. The $\mathrm{H}_{\mathrm{ex}}\left(t_{\mathrm{Fe}}\right)$ functions are very different. The absolute $\mathrm{H}_{\mathrm{ex}}$ (Fig. 2(b)) after ZFC measured at $100 \mathrm{~K}$ increases with thickness up to 8 ML and then starts to decrease. The $\mathrm{H}_{\mathrm{ex}}$ induced by MFC is larger than that of $\mathrm{ZFC}$ and unlike the latter decreases monotonically with increasing thickness. The $\mathrm{H}_{\mathrm{ex}}\left(t_{\mathrm{Fe}}\right)$ for MFC and ZFC rapidly converge as the $t_{\mathrm{Fe}}$ increases from 6 to $8 \mathrm{ML}$, and the difference becomes nearly constant around $1 \mathrm{mT}$ above $8 \mathrm{ML}$.

The region with $4<t_{\mathrm{Fe}}<6 \mathrm{ML}$ (SRT region for uncovered $\mathrm{Fe}$ ) does not show hysteresis loops in the longitudinal MOKE geometry. Hysteresis loops were observed with $\mathrm{H}$ applied perpendicular to the film plane in the polar MOKE geometry. Fig. 3 shows the hysteresis loops at $t_{\mathrm{Fe}}=5.5 \mathrm{ML}$ after ZFC and warming to $100 \mathrm{~K}$. The absence of square loops can suggest that the moments are tilted away from the perpendicular axis. For $t_{\mathrm{Fe}}<4 \mathrm{ML}$, no hysteresis loops could be measured in either longitudinal or polar MOKE geometries and after MFC or ZFC treatments. In an attempt to modify the out-of-plane moments, MFC was performed with $\mathrm{H}_{\mathrm{mfc}}$ perpendicular to the film plane and while a small increase of $5 \mathrm{mT}$ in $\mathrm{H}_{\mathrm{c}}$ was observed, no significant $\mathrm{H}_{\mathrm{ex}}$ was induced.

Structural analysis was performed using x-ray absorption near edge spectroscopy (XANES) in order to investigate the $\mathrm{Fe}$ oxidation due to both the proximity with the $\mathrm{CoO}$ and the exposure to $\mathrm{O}_{2}$ during initial $\mathrm{CoO}$ growth. Measurements were performed at the French CRG BM30B beamline at the European Synchrotron Radiation Facility (ESRF). Figure 4(a) shows the $t_{\mathrm{Fe}}$ variation of the spectra at the Fe $K$-edge. The XANES spectra in the oxidized part were compared with reference spectra of oxidized states of Fe namely, FeO, $\mathrm{Fe}_{2} \mathrm{O}_{3}$, and $\mathrm{Fe}_{3} \mathrm{O}_{4} \cdot{ }^{11}$ From $15 \mathrm{ML}$ to the lowest $\mathrm{Fe}$ coverage, the spectra changes from that of pure Fe metal to that of an Fe-oxide. A qualitative comparison excludes the presence of $\mathrm{FeO}$, since the spectra do not show the large dip around 7141 $\mathrm{eV}$ and possess higher and more structured pre-edge than the $\mathrm{FeO}$ (Fig. 4(a)). The local environment of $\mathrm{Fe}$ appears as intermediary between those in $\mathrm{Fe}_{2} \mathrm{O}_{3}$ and $\mathrm{Fe}_{3} \mathrm{O}_{4}$.

The Fe-oxide layer appears to possess a gradient of oxygen concentration giving a $\mathrm{Fe}_{2} \mathrm{O}_{3}$-like surrounding at the interface transforming to $\mathrm{Fe}_{3} \mathrm{O}_{4}$-like in deeper layers and finally to metallic Fe. From the lowest coverage up to $4 \mathrm{ML}$, the Fe layer is fully oxidized and the XANES spectra are largely unchanged. This implies that $\mathrm{O}$ has penetrated to the Fe completely for $t_{\mathrm{Fe}}<4 \mathrm{ML}$. Fitting of the spectra in the region with $t_{\mathrm{Fe}}>4 \mathrm{ML}$ was performed by taking weighted averages of the measured spectra of the mixed Fe-oxide and the reference spectra of metallic $\mathrm{Fe}$. Such a linear combination of the XANES data indicates that the thickness of the mixed Fe-oxide layer $\left(t_{\mathrm{ox}}\right)$ varies with $t_{\mathrm{Fe}}$. The oxide is formed in the whole volume of the film up to a thickness of $4 \mathrm{ML}$, then decreases linearly to $2 \mathrm{ML}$ for $t_{\mathrm{Fe}}>8 \mathrm{ML}$ (Fig. 4(b)).

The variation of $t_{\mathrm{ox}}$ is consistent with the difference of the $\varepsilon_{\mathrm{s}}\left(t_{\mathrm{Fe}}\right)$ behavior for the uncovered $\mathrm{Fe}$ and the $\mathrm{CoO} / \mathrm{Fe}$ bilayer (Fig. 1(b)). The region $t_{\mathrm{Fe}}<4 \mathrm{ML}$ with $\varepsilon_{\mathrm{S}} \sim 0$ corresponds to the XANES data where these layers are seen to be completely oxidized. This means that the disordered $\mathrm{Fe}_{1-x} \mathrm{O}_{x}$ phase does not exhibit any magneto-optic response. A possible explanation for the varying $t_{\mathrm{ox}}$ is that the first $4 \mathrm{ML}$ of $\mathrm{Fe}$ do not grow smoothly ${ }^{8}$ and there is a larger surface area (a)

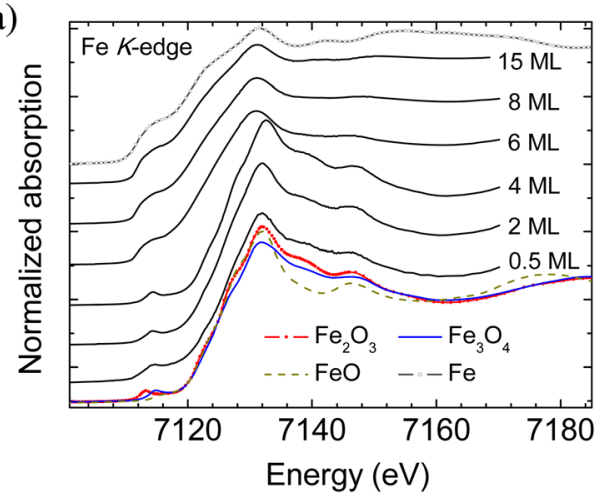

(b)

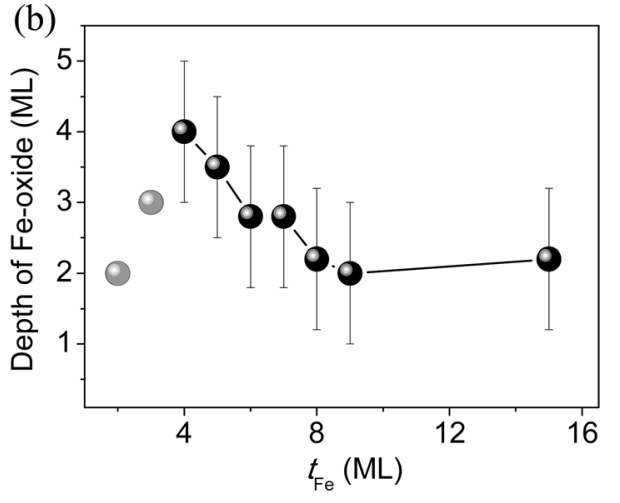

FIG. 4. (Color online) (a) XANES at the $\mathrm{Fe} K$-edge for various thicknesses of $\mathrm{Fe}$ (solid lines). Also shown are the reference spectra for the $\mathrm{Fe}_{2} \mathrm{O}_{3}, \mathrm{Fe}_{3} \mathrm{O}_{4}, \mathrm{FeO}$ and $\mathrm{Fe}$ phases for comparison and, (b) the estimated depth of the Fe-oxide, $t_{\mathrm{ox}}$, plotted against the nominal Fe thickness, $t_{\mathrm{Fe}}$. Grey dots indicate that the whole depth of Fe was oxidized $\left(t_{\mathrm{ox}}=t_{\mathrm{Fe}}\right)$. 
exposed to the oxygen. The growth mode of $\mathrm{Fe}$ on $\operatorname{Ag}(001)$ is controversial, however, there are reports that the first 3-4 ML of the film are discontinuous either due to island formation $^{12}$ or intermixing, ${ }^{13}$ and above this thickness a continuous film starts to form in a quasi-layer-by-layer mode. This fits with the XANES results which suggest that the Fe islands are completely oxidized whereas continuous layers resist oxidation due to lowered exposure to oxygen. The $t_{\mathrm{ox}}$ of $3 \mathrm{ML}$ at $t_{\mathrm{Fe}}=7 \mathrm{ML}$ agrees with Ref. 2, where $2 \mathrm{ML}$ of $\mathrm{Fe}$ was oxidized when grown on a $\mathrm{CoO}$ underlayer.

The differences in the $\mathrm{H}_{\mathrm{c}}$ and $\mathrm{H}_{\mathrm{ex}}$ of the sample after the ZFC and MFC procedures are due to the effect of interfacial defects in the $\mathrm{CoO} / \mathrm{Fe}$ bilayer. The roughness of the precovered $\mathrm{Fe}$ and subsequent formation of $\mathrm{Fe}_{1-x} \mathrm{O}_{x}$ introduces interfacial defects that weaken the exchange coupling. Saturating the sample in $550 \mathrm{mT}$ field and cooling below $T_{\mathrm{N}}$ forces exchange coupling in the defect containing regions. With increasing $t_{\mathrm{Fe}}$, the $t_{\mathrm{ox}}$ decreases suggesting an increased interfacial smoothness and reduced exposure of the Fe surface to the $\mathrm{CoO}$. This results in a reduced number of defects with increasing Fe thickness.

In Fig. 1(a), it is clear that 6 ML thick Fe is ferromagnetic at $295 \mathrm{~K}$ and the Curie temperature is well above this temperature. The $T_{\mathrm{N}}$ of $\mathrm{CoO}$ is slightly below $295 \mathrm{~K}$. During ZFC from $350 \mathrm{~K}$ as the temperature drops below $T_{\mathrm{N}}$ the AFM is ordered in the presence of the remnant moments of the FM layer. This causes the AFM spins to orient along specific directions governed by the field from the FM, thus inducing exchange bias. Further lowering of the temperature results in the increase in anisotropies of both layers. It is possible for a fraction of AFM moments to realign along their magneto-crystalline easy axes and form AFM domains (due to bulk defects in the AFM layer). Domain formation in the AFM can rotate FM moments in regions where the FM anisotropy is lowered by the existence of interfacial defects. A fraction of FM moments may therefore be misaligned and reduce the exchange bias. MFC can force the Fe moments in the defect regions to remain aligned and also influence the domain formation in the $\mathrm{CoO}$ thereby stabilizing the $\mathrm{Fe}$ moments along the field direction, and increasing the exchange bias compared to that of ZFC.

Indeed in Fig. 2(b) below $8 \mathrm{ML}$, the exchange bias induced by ZFC is lower than that due to MFC and the difference gradually reduces and remains fixed at $0.05 \mathrm{mT}$ above 8 ML Fe thickness. This variation suggests that the interfacial defect density decreases with increasing Fe thickness, and is supported by the depth variation of the Fe-oxide layer which also decreases and saturates at $8 \mathrm{ML}$ of Fe (Fig. 4). Residual defects may persist such that the $550 \mathrm{mT}$ MFC is insufficient to compensate for the lowered exchange coupling in those regions, and exchange bias induced by ZFC remains lower by a fixed value compared to the $\mathrm{H}_{\mathrm{ex}}$ induced by MFC (Fig. 2(b)). The defect induced reduction in $\mathrm{H}_{\mathrm{ex}}$ for the ZFC case compared to that of MFC points to a dependence of $\mathrm{H}_{\mathrm{ex}}$ on $\mathrm{H}_{\mathrm{mfc}}$. For $6<t_{\mathrm{Fe}}<8 \mathrm{ML}$, varying the $\mathrm{H}_{\mathrm{mfc}}$ may provide an effective degree of freedom to control $\mathrm{H}_{\mathrm{ex}}$. Thus interfacial defects may be used to adjust the switching field in thin film devices.

Due to practical limitations on the gradient of the wedge the variation of $\mathrm{H}_{\mathrm{ex}}, \mathrm{H}_{\mathrm{c}}$, and $t_{\mathrm{ox}}$ between 9 and $15 \mathrm{ML}$ could not be measured. However, we note that the difference in $\mathrm{H}_{\mathrm{c}}$ and $\mathrm{H}_{\mathrm{ex}}$ for MFC and ZFC clearly converge at $8 \mathrm{ML}$ and this is retained at $15 \mathrm{ML}$. Similarly the oxide depth is nearly the same $\left(t_{\mathrm{ox}}=2 \mathrm{ML}\right)$ for $t_{\mathrm{Fe}}=8$ to $9 \mathrm{ML}$ and $15 \mathrm{ML}$. Furthermore the well documented layer-by-layer growth mode of $\mathrm{Fe}$ on $\mathrm{Ag}(001)$ in this thickness regime corroborates that no further change to the interface structure can be expected for $t_{\mathrm{Fe}}$ $>8 \mathrm{ML}$.

In conclusion, by combining MOKE and XANES on a $\mathrm{CoO} / \mathrm{Fe}$-wedge/ $\mathrm{Ag}(001)$ sample we correlate the depth of the interfacial $\mathrm{Fe}$ oxide to the magnetic behaviour: (a) zero magneto-optic Kerr response up to 4 ML Fe thickness due to complete Fe oxidation, (b) spin reorientation transition from out-of-plane to lying in-plane at $6 \mathrm{ML} \mathrm{Fe,} \mathrm{(c)} \mathrm{decreasing}$ interfacial defects up to $8 \mathrm{ML} F$ resulting in reducing differences between exchange bias and coercivity from magnetic and zero field cooling and d) above 8 ML Fe thickness where the oxide depth remains constant and magnetic and zero field cooling result in similar magnetic behaviour. The dependence of the depth of the interfacial oxidation on the precovered metallic layer is linked to the growth mode of the metallic layer and other oxide/metal systems may also exhibit similar thickness dependent features. The correlation of the interfacial oxide to the magnetic behaviour may aid the optimization of several oxide/metal exchange bias and spintransport devices.

Technical support from $\mathrm{H}$. Menge and W. Greie is acknowledged. M.M.S. acknowledges the $\mathrm{PhD}$ grant from the Fondation Nanosciences, Grenoble, France.

${ }^{1}$ C. Tiusan, J. Faure-Vincent, C. Bellouard, M. Hehn, E. Jouguelet, and A. Schuhl, Phys. Rev. Lett. 93, 106602 (2004).

${ }^{2}$ T. J. Regan, H. Ohldag, C. Stamm, F. Nolting, J. Lüning, J. Stöhr, and R. L. White, Phys. Rev. B 64, 214422 (2001).

${ }^{3}$ R. Abrudan, J. Miguel, M. Bernien, C. Tieg, M. Piantek, J. Kirschner, and W. Kuch, Phys. Rev. B 77, 014411 (2008).

${ }^{4}$ S. Yuasa, T. Nagahama, A. Fukushima, Y. Suzuki, and K. Ando, Nature Mater. 3, 868 (2004).

${ }^{5}$ J. Wu, J. S. Park, W. Kim, E. Arenholz, M. Liberati, A. Scholl, Y. Z. Wu, Ch. Hwang, and Z. Q. Qiu, Phys. Rev. Lett. 104, 217204 (2010).

${ }^{6}$ M. Stampanoni, A. Vaterlaus, M. Aeschlimann, and F. Meier, Phys. Rev. Lett. 59, 2483 (1987).

${ }^{7}$ Z. Q. Qiu, J. Pearson, and S. D. Bader, Phys. Rev. Lett. 70, 1006 (1993).

${ }^{8}$ D. M. Schaller, D. E. Bürgler, C. M. Schmidt, F. Meisinger, and H.-J. Güntherodt, Phys. Rev. B 59, 14516 (1999).

${ }^{9}$ J. S. Park, J. Wu, E. Arenholz, M. Liberati, A. Scholl, Y. Meng, Ch. Hwang, and Z. Q. Qiu, Appl. Phys. Lett. 97, 042505 (2010).

${ }^{10}$ T. Ambrose and C. L. Chien, Phys. Rev. Lett. 76, 1743 (1996).

${ }^{11}$ S.-H. Chou, J. Guo, and D. E. Ellis, Phys. Rev. B 34, 12 (1986).

${ }^{12}$ H. Li, Y. S. Li, J. Quinn, D. Tian, J. Sokolov, F. Jona, and P. M. Marcus, Phys. Rev. B 42, 9195 (1990).

${ }^{13}$ A. Hahlin, C. Andersson, J. Hunter Dunn, B. Sanyal, O. Karis, and D. Arvanitis, Phys. Rev. B 73, 134423 (2006). 